\title{
Improving hole exit quality in rotary ultrasonic machining of ceramic matrix composites using a compound step-taper drill
}

\author{
Jianjian Wang ${ }^{1,2}$, Pingfa Feng ${ }^{* 1,2,3}$, Jingzhen Zheng ${ }^{4}$, Jianfu Zhang ${ }^{1,2}$
}

1. State Key Laboratory of Tribology, Department of Mechanical Engineering, Tsinghua University, Beijing, 100084, China

2. Beijing Key Lab of Precision/Ultra-precision Manufacturing Equipments and Control, Beijing, 100084, China 3 Division of Advanced Manufacturing, Graduate School at Shenzhen, Tsinghua University, Shenzhen, 518055, China

4. Beijing Xinghang Mechanical-Electrical Equipment Co., Ltd, Beijing, 100074, China

Mechanical-machining-induced tearing defects at hole exits restrict the application of $\mathrm{C} / \mathrm{SiC}$ composites. Rotary ultrasonic machining (RUM) is suitable for hole manufacture in brittle composites, providing reduced tearing size as compared with conventional grinding. Even so, substantial tearing defects at the hole exit remain with RUM. In this study, a novel compound steptaper diamond core drill for RUM of $\mathrm{C} / \mathrm{SiC}$ was developed to further improve the hole exit quality. Contrastive machining tests were conducted to evaluate the effectiveness of the new type drill. Experimental results show that the compound drill can help reduce the tearing size by $30 \%$ on average. Results of variance analysis indicate that there is little dependency of tearing size on processing variables with the compound drill, whereas the common drill shows substantial dependence. Detailed observation of the thrust force reveals that the tearing size reduction using the compound drill is due to the reprocessing effects of its taper face. In the reprocessing process of the taper face, the thrust force gradually decreases at the hole exit. Increasing the ultrasonic amplitude can help further improve the hole exit quality when using our compound drill.

Keywords: Rotary ultrasonic machining, Hole exit quality, Drill design, Ceramics matrix composites, Hole drilling, $\mathrm{C} / \mathrm{SiC}$

\footnotetext{
${ }^{*}$ Corresponding author: Pingfa Feng at Department of Mechanical Engineering, Tsinghua University, 100084, Beijing, China, fengpf@mail.tsinghua.edu.cn, phone number: +86 10 62797859, fax number: +86 1062797859.
} 


\section{Introduction}

In the twenty-first century new stronger and tougher structural materials are needed to meet the challenges of diverse strategic fields from construction to transportation and energy. Fiber-reinforced ceramic matrix composites (FRCMCs), including $\mathrm{C} / \mathrm{C}, \mathrm{C} / \mathrm{SiC}$, and $\mathrm{SiC} / \mathrm{SiC}$, have emerged as potential candidates for their superior physical and mechanical properties [1]. They are heterogeneous materials which combine the ceramic's high strength, hardness, and temperature stability with the reinforcing fiber's high toughness. Compared with their pure ceramic analogues, FRCMCs are more resilient against crack propagation, resulting in no reported disastrous accidents to date [2]. FRCMCs have proven to be useful structural materials for jet engine exhaust ducts, aero foil leading edges, nose cones, and other heat-stressed components [3].

To manufacture products from FRCMCs, a shape-forming technology is necessary. Machining is usually needed to make the FRCMC material satisfy the assembly and application requirements [4]. The hardness and brittleness of FRCMCs however make them one of the most difficult-to-machine materials available. Improving the efficiency and reducing the cost of machining FRCMCs has thereby drawn considerable research attention. In the past two decades various conventional and novel methods have been introduced to attempt to improve the machining of FRCMCs, including rotary ultrasonic machining (RUM) [5-8], grinding [4, 9-13], electrical discharge machining [14], laser machining [15], abrasive water jet machining [16], ultrasonic machining [17], ultrasonic vibration-assisted grinding [18], and ultrasonic vibration-assisted filing [19].

A hole is one of the most common features that must be machine into FRCMCs. Usually, the primary concern when drilling brittle materials such as ceramics and glasses is edge chipping at the hole exit [20-21]. Due to the local inhomogeneity of FRCMCs however, tearing is a more significant concern [5]. Such tearing at the hole exit can significantly impact the reliability of the final component. The hard ceramic phase of FRCMCs furthermore prevents the use of conventional drilling methods, such as with a twist drill, which would normally suffice for carbon-fiber reinforced polymers. Rotary ultrasonic machining (RUM) is a hybrid machining process that is considered suitable for hole production in hard and brittle materials [7]. It combines the material removal mechanisms of diamond grinding and ultrasonic machining. As shown in Fig.1, in RUM, a hollow rotating tool with metal-bonded diamond abrasives is ultrasonically vibrated in the axial direction while feeding towards the workpiece at a constant feed rate. RUM have already been demonstrated to be suitable for machining FRCMCs, providing a lower cutting force, improved hole surface integrity, higher material removal rate, and smaller tearing size. Even so, obvious tearing is still observed at the hole exit [5].

In this study, a novel compound step-taper diamond core drill was designed to help further reduce the tearing size for RUM of FRCMCs. C/SiC was selected as the material for machining tests to evaluate the effectiveness of this new type of drill. Detailed observations of the thrust force were made to reveal the mechanism of edge chipping reduction. 


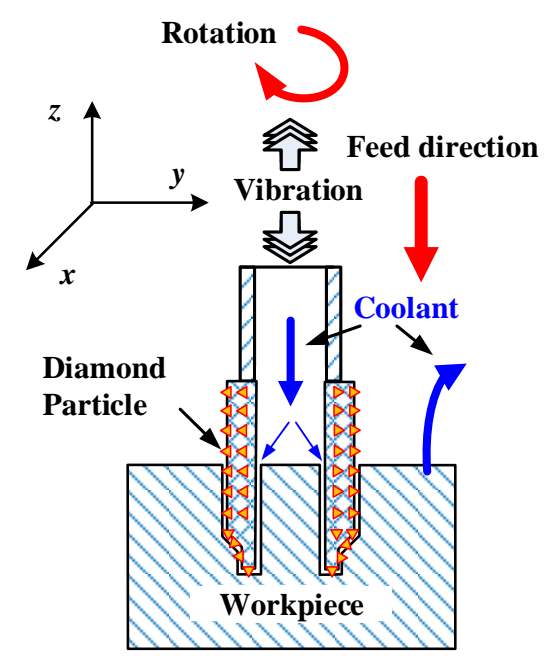

Fig. 1 Illustration of RUM using our compound step-taper drill.

\section{Experiment design}

\subsection{Experimental setup}

The rotary ultrasonic machine we used in this study as an Ultrasonic 50 (DMG). It is composed of an ultrasonic spindle, a feed system, and a coolant supply system. The maximum rotation speed of the ultrasonic spindle was $6,000 \mathrm{rpm}$. The ultrasonic spindle, comprised of a power supply, a piezoelectric transducer, an ultrasonic horn, and a diamond core drill, is the key component of the ultrasonic machine. The power supply converts a $50 \mathrm{~Hz}$ AC electrical current to an ultrasonic frequency output. The piezoelectric transducer converts the $\mathrm{AC}$ input into mechanical vibrations with ultrasonic frequency (around $20 \mathrm{kHz}$ ). Because the output vibrational amplitude of the transducer is too small to be directly applied to machining materials, the ultrasonic horn is designed to amplify the ultrasonic vibration into a usable value. Simultaneously, the diamond core drill should be matched with the ultrasonic horn to guarantee that an efficient ultrasonic vibration at the drill nose can be produced.

As illustrated in Fig.2, a fixture mounted on a dynamometer (Kistler 9256C2) was used to hold the workpiece using two clamps. A hole with diameter of $20 \mathrm{~mm}$ and depth of $12 \mathrm{~mm}$ was previously machined on the fixture to protect the drill against knocking. Two pieces of air-laid paper were used between the clamp and workpiece to protect the workpiece. Two different types of diamond core drills were used to machine the $\mathrm{C} / \mathrm{SiC}$ workpiece. One was a common drill, the other was the compound step-taper drill. The dimensions of their drill heads are shown in Fig.2(b) and (c). The diamond grit size of both drills was D107. The diamond core drills were mounted on the ultrasonic spindle with an ER16 cone. 

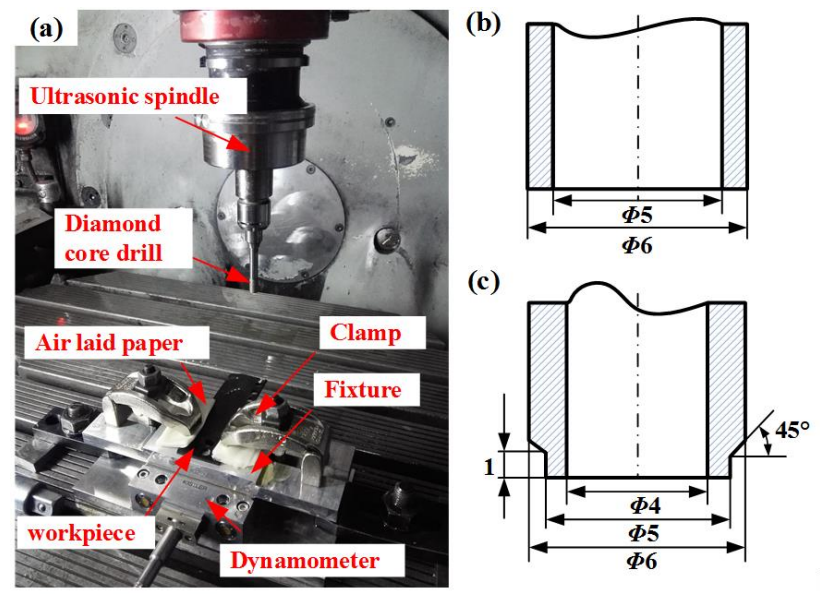

Fig. 2 Illustration of experimental setup. (a) Fixturing scheme (b) Dimensions of common drill. (c) Dimensions of compound drill.

\subsection{Experimental conditions}

To evaluate the effectiveness of the compound drill on the tearing reduction in the RUM of $\mathrm{C} / \mathrm{SiC}$ composites, a series of experiments was conducted to obtain tearing size data. The workpiece samples used were two $95 \mathrm{~mm} \times 30 \mathrm{~mm} \times 3 \mathrm{~mm} \mathrm{2D} \mathrm{C/SiC}$ composites panels. Fig. 3 shows the structure of the 2D C/SiC panel. Fig. 3(a) is a 200X partially enlarged view of the bottom surface of the panel. No fibers are observed. Fig. 3(b) is a 1600X SEM image of the upper surface of the panel, where carbon fibers in $90^{\circ}$ and $0^{\circ}$ orientations can be distinguished. The tool drilled from the upper surface to the bottom surface. Fig. 3(c) is a 100X microscopy image of the side surface, where $90^{\circ}-$ and $0^{\circ}$-oriented fiber bundles are observed in addition to voids. Fig. 3(d) is a 400X SEM image along the longitudinal direction of a fiber bundle. Individual carbon fibers can be distinguished. The $\mathrm{C} / \mathrm{SiC}$ panel was made using CVI. A C/SiC panel was separated from the middle interlayer in two panels. That is why the morphologies of the upper surface and bottom surface are different.
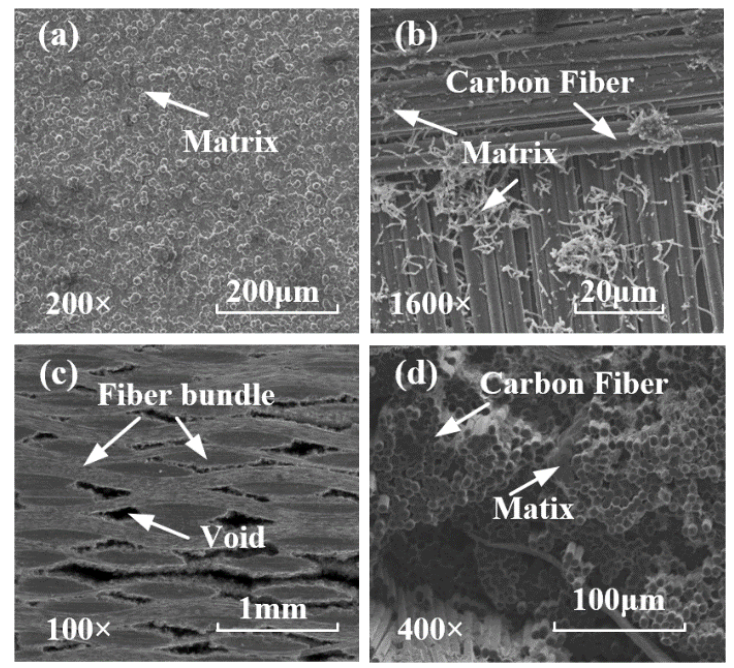

Fig. 3 Microscopic and SEM images of the C/SiC composites. (a) 200 times microscopy image of bottom surface. (b) 1600 times SEM image of up surface. (c) 100 times microscopy image of side surface. (d) 400 times SEM image 
in longitudinal direction of fiber bundle.

Experimental measurements of spindle speed, feed rate, and ultrasonic amplitude are provided in Table 1. Each group of machining tests was conducted twice to reduce random error. Ideally, in order to compare the efficiency of the common drill and compound drill the experiments should be performed at the same ultrasonic frequencies and amplitudes. However, the Ultrasonic 50 cannot change the ultrasonic amplitude freely by modulating the input voltage or current. Rather, the ultrasonic machine is tuned at its resonant frequency, where the ultrasonic amplitude is maximal. The resonant frequencies and amplitudes are different however for the different drills. In Table 1 we report the differences in ultrasonic frequencies and amplitudes between the common drill and compound drill. Fortunately, those differences are small enough to be neglected for our needs.

Two compound drills were used in the experiment. They were manufactured to the same specifications with the same equipment. Even so, small manufacturing variations, particularly in the use of the ER16 cone, yielded different resonant frequencies and amplitudes for the two drills. We exploit that difference to investigate the effect of ultrasonic amplitude on the performance of the compound drill.

The ultrasonic power was monitored during the machining process to guarantee that the ultrasonic machine was working well. Both inner and outer coolant lines were used during the machining process.

Table 1 Machining variables

\begin{tabular}{ll}
\hline Parameters & Value \\
\hline Spindle speed $S(\mathrm{rpm})$ & $2000,4000,6000$ \\
Feed rate $f_{\mathrm{r}}(\mathrm{mm} / \mathrm{min})$ & $1,2,3$ \\
Tool & common drill, compound drill \\
Ultrasonic frequency $f(\mathrm{kHz})$ & 18.45 for common drill, \\
& 18.10 and 18.15 for two compound drills respectively \\
Ultrasonic amplitude $A(\mu \mathrm{m})$ & 7 for common drill, \\
& 8 and 14 for two compound drills respectively \\
\hline
\end{tabular}

\subsection{Measurement method}

A laser fiber vibrometer (LKH008, KEYENCE, Japan) with maximum sampling frequency of 392 $\mathrm{kHz}$ and a resolution ratio of $0.1 \mu \mathrm{m}$ was used to measure the ultrasonic amplitude of the diamond core drill. The laser spot was aimed at the tool end to obtain the vibrational curve of the diamond core drill. The ultrasonic amplitude can then be calculated.

The dynamometer was used to measure the drilling forces during the machining process. The drilling force signal from the dynamometer was recorded with a data acquisition card after being amplified by a charge amplifier (5070A). The recorded data were then saved and processed with commercial software (Dynoware). The measurement sampling frequency was set at $1000 \mathrm{~Hz}$. Fig.4 shows a typical thrust force (the force along the axial direction of drill) curve $v s$. time. It can be seen that at $t_{0}$ time, the thrust force falls abruptly, indicating the formation of tearing at the hole exit. 


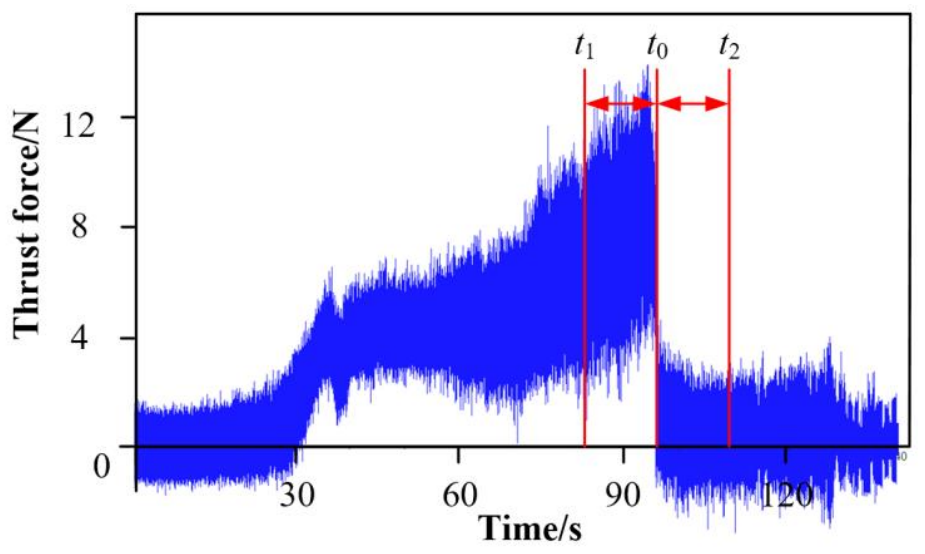

Fig. 4 Definition of tearing force

In this study, the tearing force was defined as the driving force which directly promotes the formation of tearing damage at the hole exit. As shown in Fig.4, an average value was used as an analysis index, which could be calculated with the following equation:

$$
F_{\mathrm{t}}=\frac{\int_{t_{1}}^{t_{0}} F d t}{t_{0}-t_{1}}-\frac{\int_{t_{0}}^{t_{2}} F d t}{t_{2}-t_{0}}
$$

where $t_{0}-t_{1}=t_{2}-t_{0}=0.2 / f_{\mathrm{r}}, f_{\mathrm{r}}$ is the feed rate in $\mathrm{mm} / \mathrm{min}, t_{0}$ is the time when the tearing forms, the units of $t_{0}, t_{1}$ and $t_{2}$ are s. 0.2 in mm means the feeding distance of drill in $t_{0}-t_{1}$ or $t_{2}-t_{0}$ time.

A SEM (QUANTA 200 FEG, FEI, Hillsboro, America) was used to inspect the hole exit. Fig. 5 reproduces a characteristic SEM image of the hole exit. In Fig. 5, several types of defect are observed, including edge chipping, burrs, and tearing. The burr occurs when a fiber is not completely removed, projecting into the hole. 'Edge chipping' denotes matrix fracture at the hole exit. 'Tearing' denotes fiber fracturing, exposing other fibers. SEM images indicate that tearing is by far the most frequent type of defect at the hole exit. We therefore use the tearing size as a metric to evaluate the effectiveness of the compound drill i.e. hole exit quality.

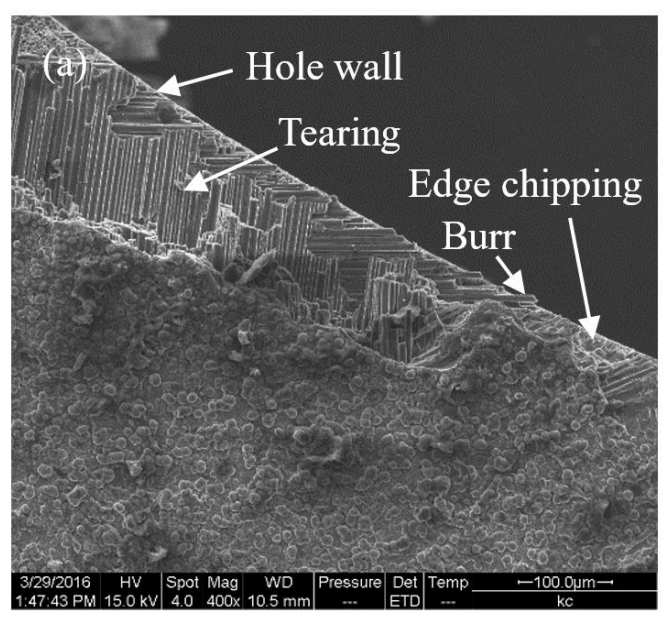

Fig. 5 SEM image of the hole exit

An optical microscope (55XA, Shanghai Optical Instrument Factory No.6., Shanghai, China) was 
used to evaluate tearing size at the exit of each machined hole. Fig. 5 shows the definition of tearing size at hole exit. $D_{\mathrm{h}}$ is the hole diameter and $D_{\mathrm{m}}$ is the diameter of the smallest circle which circumscribes the tearing damage. Two tearing size indices were used in this study to evaluate the effectiveness of the compound drill, one is the maximum tearing size $t_{m}$, and the other is the average tearing size ta. They can be calculated by Eq. (2) and Eq. (3), where $A_{\mathrm{t}}$ is the tearing area.

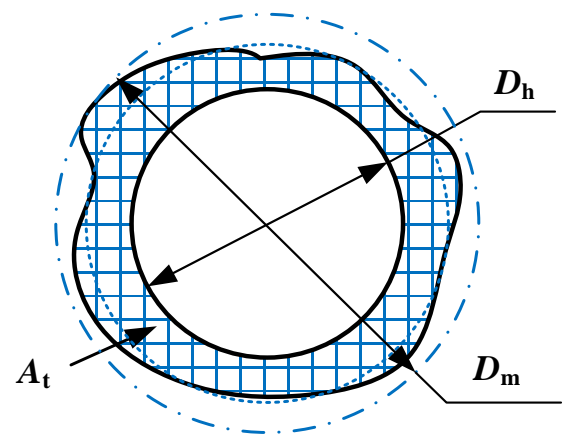

Fig. 6 Definition of tearing size at hole exit

$$
\begin{aligned}
& t_{\mathrm{m}}=\frac{D_{\mathrm{m}}-D_{\mathrm{h}}}{2} \\
& t_{\mathrm{a}}=\frac{A_{\mathrm{t}}}{\pi D_{\mathrm{h}}}
\end{aligned}
$$

\section{Results}

\subsection{Damage characteristics at hole exit}

Fig.7 compares the hole exit using different drills with a feed rate of $2 \mathrm{~mm} / \mathrm{min}$ and spindle speed of $2000 \mathrm{rpm}$. Tearing defects at the hole exit using common drill were much more serious when using the compound drill. Hardly any macroscopic tearing can be observed in Fig. 7(a). A superior hole exit was obtained with the use of the compound drill. In the following section we make a detailed quantitative comparison.
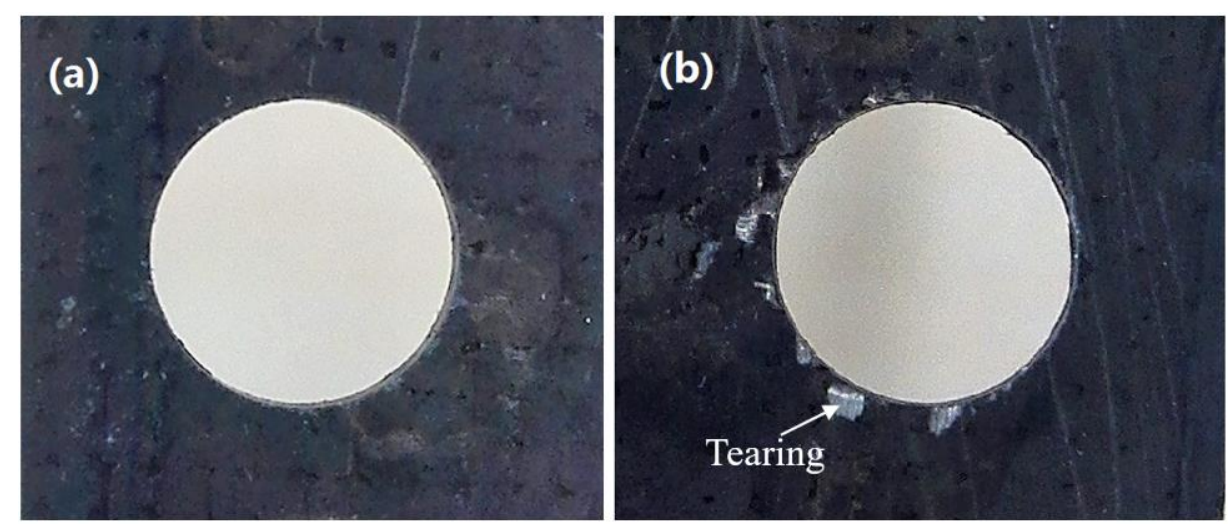

Fig. 7 Comparison of hole exit using different drills. (a) using compound drill. (b) using common drill. 


\subsection{Verification of tearing reduction using the compound drill}

Figs. 8 and 9 show the maximum tearing size and the average tearing size respectively for different processing variables. Compared to using the common drill, using the compound drill yields lower maximum tearing sizes across all processing variables. The average tearing sizes are also reduced using the compound drill except under a few particular conditions. The reduction rates are illustrated in Table 2. The use of the compound drill can reduce the maximum tearing size by $5.7 \%$ to $73.1 \%$. For the average tearing size, this ratio is $-11.4 \%$ to $71.7 \%$. The average reduction ratio for maximum tearing size is $31.9 \%$ and for average tearing size is $25.5 \%$. The tearing reduction is more significant when the spindle speed is $2000 \mathrm{rpm}$.

As shown in Figs. 8 and 9, the processing variables have a significant impact on tearing size. When a common drill is used, the tearing size increases with increasing feed rate but decreases with increasing spindle speed. Those dependencies weaken however with the compound drill. For example, when using the compound drill, increasing the spindle speed does not further decrease the tearing size significantly.

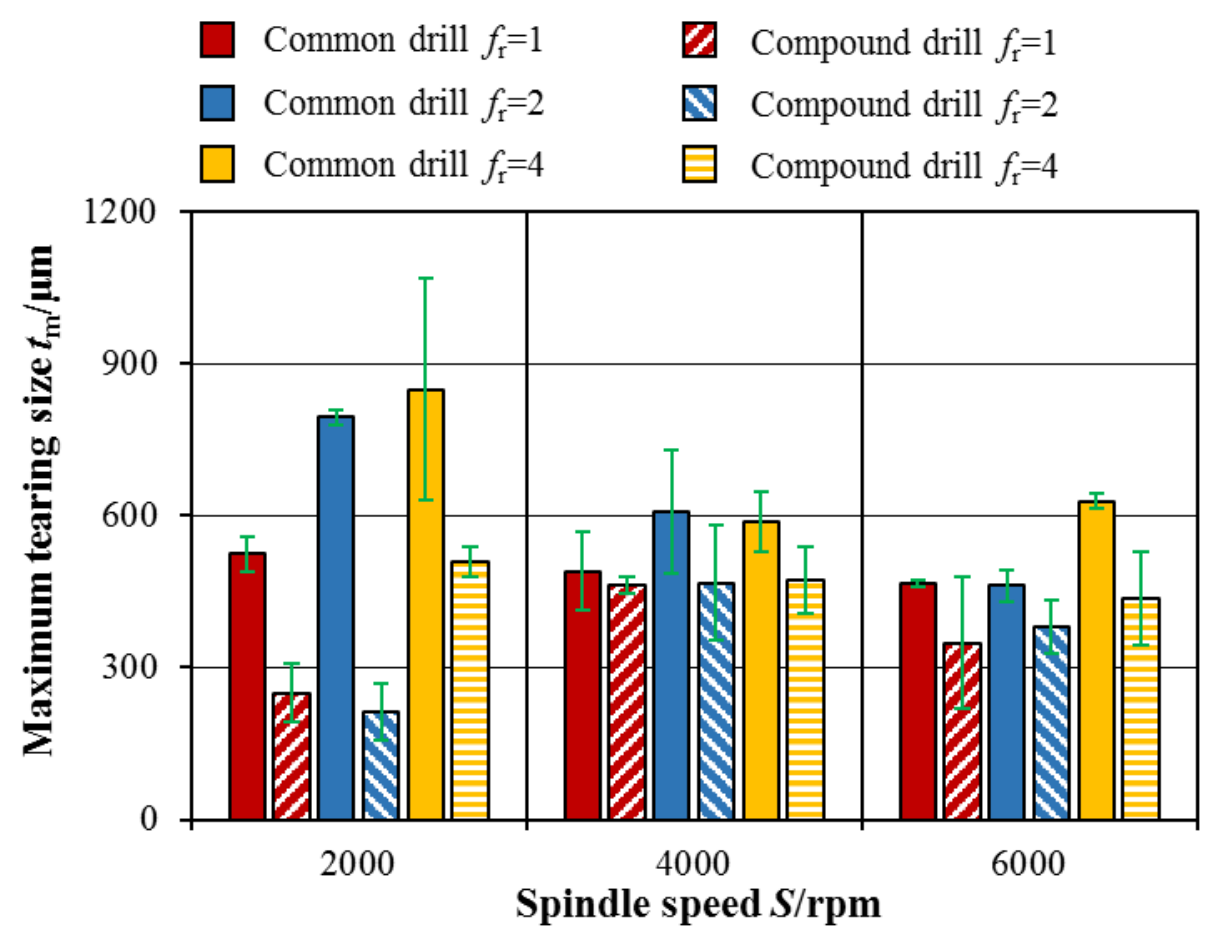

Fig. 8 Maxmimum tearing size using different drills and conditions 


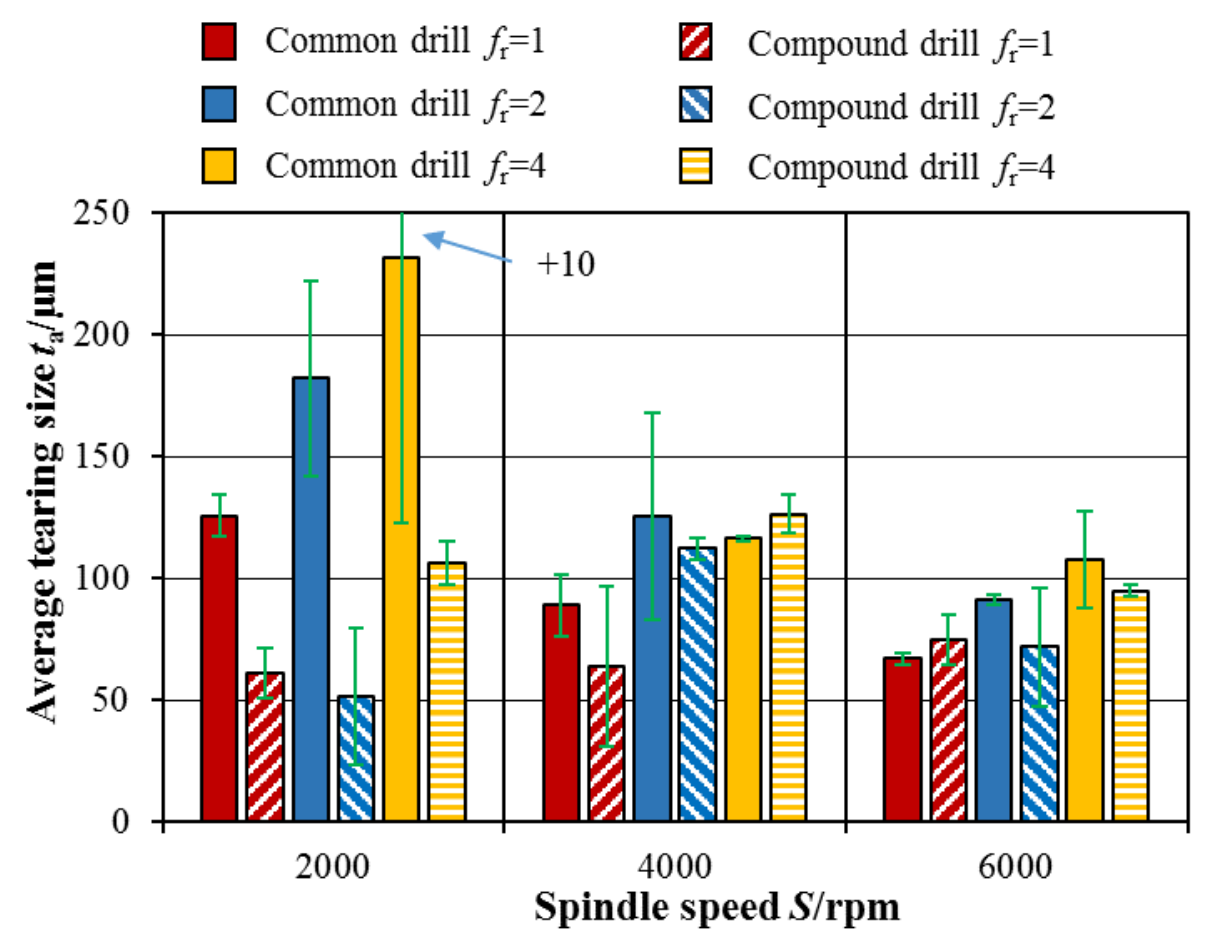

Fig. 9 Average tearing size using different drills and conditions

Table 2 Reduction ratio of tearing size using the compound drill

\begin{tabular}{llll}
\hline$S(\mathrm{rpm})$ & $f_{\mathrm{r}}(\mathrm{mm} / \mathrm{min})$ & $\begin{array}{l}\text { Reduction } \\
\text { ratio of } t_{\mathrm{m}}\end{array}$ & $\begin{array}{l}\text { Reduction } \\
\text { ratio of } t_{\mathrm{a}}\end{array}$ \\
\hline 2000 & 1 & $52.4 \%$ & $51.2 \%$ \\
2000 & 2 & $73.1 \%$ & $71.7 \%$ \\
2000 & 4 & $40.1 \%$ & $54.2 \%$ \\
4000 & 1 & $5.7 \%$ & $28.2 \%$ \\
4000 & 2 & $23.1 \%$ & $10.7 \%$ \\
4000 & 4 & $19.6 \%$ & $-8.6 \%$ \\
6000 & 1 & $25.3 \%$ & $-11.4 \%$ \\
6000 & 2 & $17.3 \%$ & $21.3 \%$ \\
6000 & 4 & $30.5 \%$ & $12.2 \%$ \\
Average value & $31.9 \%$ & $25.5 \%$ \\
\hline
\end{tabular}

Significance analysis was used to quantitatively characterize the extent to which processing variables affect tearing size. The results are listed in Table 3. The percentages represent the probability that variations in that processing variable do not affect the tearing size at all. A higher probability means a smaller effect of that processing variable on the tearing size. When using compound drill, the dependency of tearing size on the spindle speed and feed rate is indeed less significant than when using the common drill. There is almost no combined interaction effect of spindle speed and feed rate on tearing size for either drill. It can therefore be concluded that the compound drill provides superior performance without adjustment of the processing variables; in practical machining, the compound drill is more tolerant to error by the workers with low experience. 
At the same time, with the compound drill there is less opportunity to reduce tearing size by optimizing the processing variables.

Table. 3 Results of significance analysis

\begin{tabular}{lllll}
\hline Factor & $\begin{array}{l}t_{\mathrm{m}} \text { using } \\
\text { common drill }\end{array}$ & $\begin{array}{l}t_{\mathrm{m}} \text { using } \\
\text { compound drill }\end{array}$ & $\begin{array}{l}t_{\mathrm{a}} \text { using } \\
\text { common drill }\end{array}$ & $\begin{array}{l}t_{\mathrm{a}} \text { using compound } \\
\text { drill }\end{array}$ \\
\hline Spindle speed & $10.43 \%$ & $24.50 \%$ & $7.23 \%$ & $9.36 \%$ \\
Feed rate & $8.28 \%$ & $22.37 \%$ & $1.55 \%$ & $25.75 \%$ \\
Interaction effect & $53.13 \%$ & $38.56 \%$ & $88.78 \%$ & $45.12 \%$ \\
\hline
\end{tabular}

\subsection{Mechanism of tearing reduction using compound drill}

We can identify the mechanism of compound drill tearing reduction by analyzing the thrust force. Fig. 10 shows the typical drilling forces (thrust forces) vs. time for a feed rate of $2 \mathrm{~mm} / \mathrm{min}$ and spindle speed of $6000 \mathrm{rpm}$ using the compound drill and the common drill. In order to observe the drilling force more clearly, a low-pass filter with a cut-off frequency of $10 \mathrm{~Hz}$ was used to process the raw data. The thrust force using the compound drill shows quite a different variation compared to the common drill. To help us to understand the detailed drilling processes, we separate the thrust force $v s$. time curves into several parts.

In both drills, the thrust forces increase with increasing drilling depth. That is due to the material characteristics of $\mathrm{C} / \mathrm{SiC}$. The $\mathrm{C} / \mathrm{SiC}$ panel is made using $\mathrm{CVI}$. As a result, the degree of densification near the surface is higher than the bulk. From state 3 to state 4 when using the compound drill, or from state 1 to state 2 when using the common drill, the thrust force drops abruptly indicating the formation of tearing. The unique feature of the thrust force curve $v s$. time behavior using the compound drill is the existence of states 4 and 5. In state 4, reprocessing, the thrust force increases because the taper face of the compound drill continues to machine the material. However, in state 5 the thrust force decreases gradually due to the decreasing contact area between the tool taper face and the material. In state 2 when using common drill, there exists a similar decline in thrust force because the tearing shape is not homogeneous. In that case the tearing size is not reduced however because the bulk of tearing has already occurred.
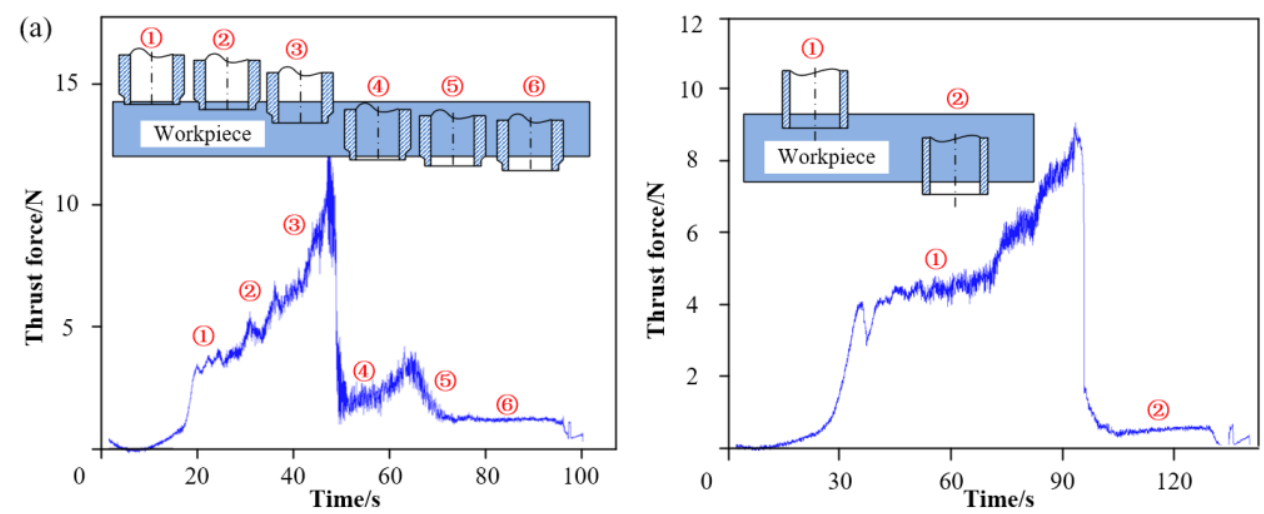

Fig. 10 Drilling force characteristics using different drills.10Hz low-pass filter. 

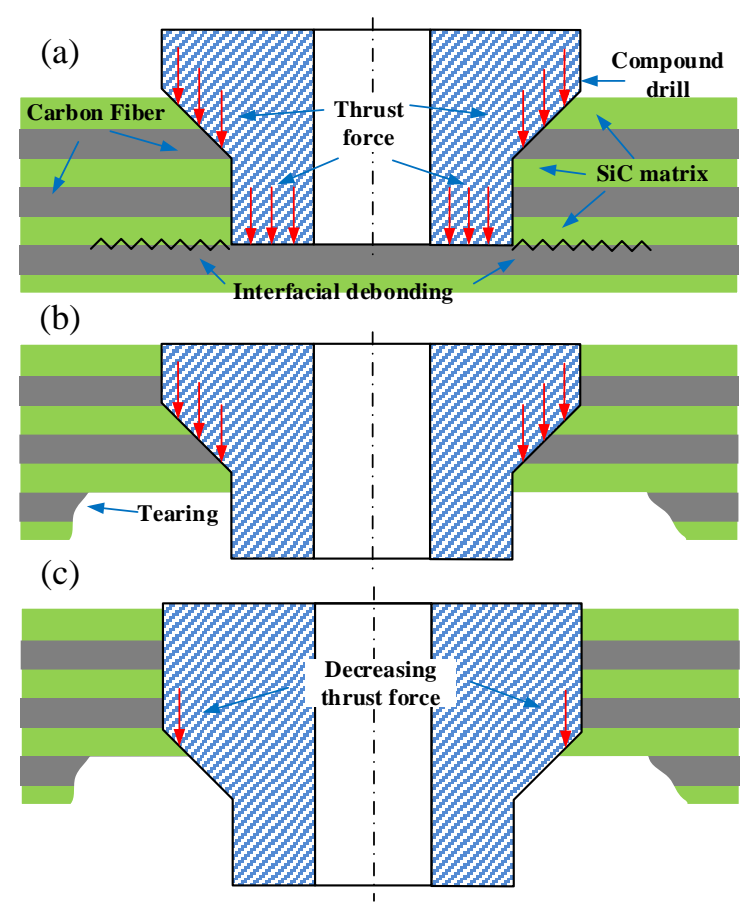

Fig. 11 Illustration of the mechanism of tearing size reduction using the compound drill.

Fig. 11 illustrates the formation process of tearing when using the compound drill. In Fig. 11(a), the interface between the matrix and fiber begins to be deboned with the driving effect of the thrust force from the end face of the drill. In Fig. 11(b), the fibers fracture, resulting in the formation of tearing. At this time, the thrust force drops abruptly. In Fig. 11(c), the taper face of the compound drill is going to finish the drilling, corresponding to state 5 in Fig. 10(a). In this state, the contact area between the drill taper face and the material decreases gradually, resulting in the gradual decrease of the thrust force, which suppresses the formation of new tearing. In addition, the role of the step of drill is to separate the tearing from reprocessing.

\subsection{Effect of ultrasonic amplitude}

Fig. 12 shows the effect of ultrasonic amplitude on tearing size with a spindle speed of $4000 \mathrm{rpm}$. For both feed rates, increasing the ultrasonic amplitude from $8 \mu \mathrm{m}$ to $14 \mu \mathrm{m}$ dramatically reduces the tearing size. Thus, in the practical drilling of $\mathrm{C} / \mathrm{SiC}$, one can further improve the hole exit quality by increasing the ultrasonic amplitude when using the compound drill. The effect of ultrasonic amplitude on the tearing size when drilling $\mathrm{C} / \mathrm{SiC}$ composites is notably different from its effect on the edge chipping size when drilling homogeneous brittle materials such as sapphire. The edge chipping size does not obviously depend on the ultrasonic amplitude [20]. This difference may be resulted from the differing formation mechanisms of tearing and edge chipping. The formation of edge chipping at the hole exit is due to the propagation of machining-induced cracks, driven by the drilling force. From the SEM images of tearing however we know that it forms due to fiber fracture. Edge chipping can therefore form at any location of material while tearing only appears at the interface of the matrix and the fibers. That is why the shape of edge chipping is generally continuous and smooth while tearing is intermittent. 


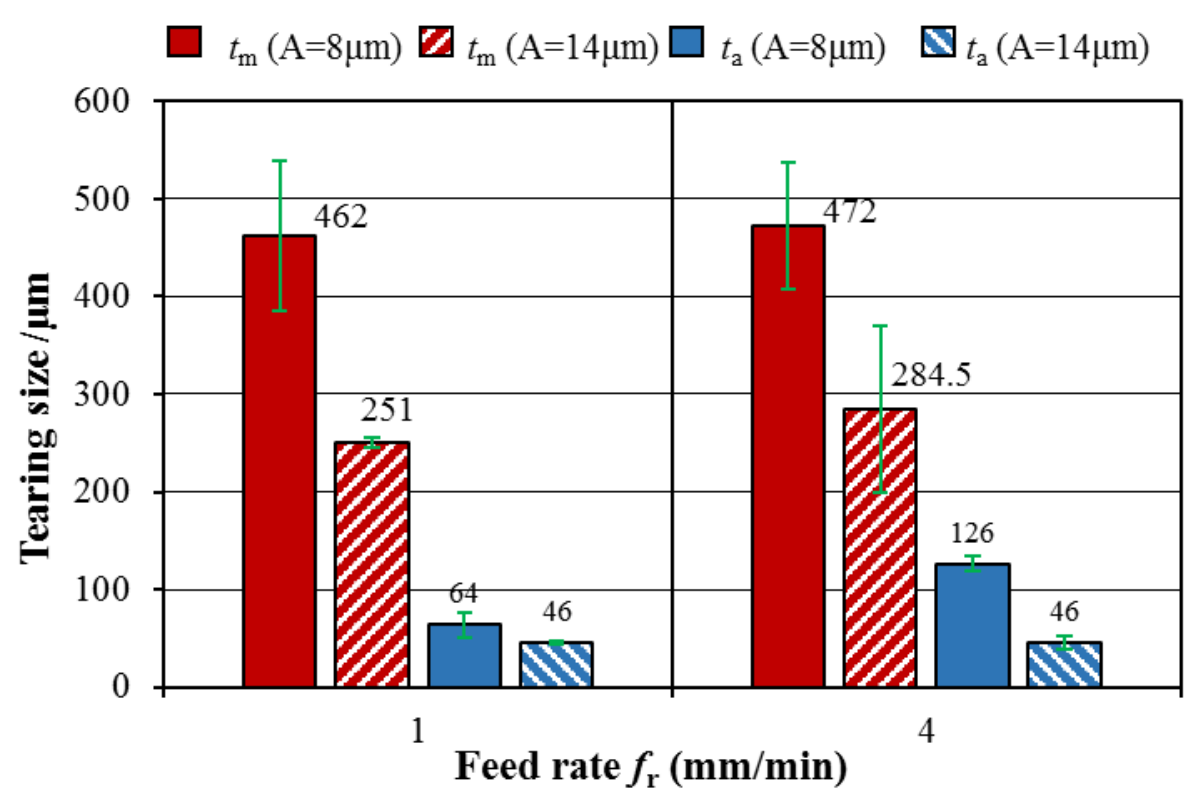

Fig. 12 Effect of ultrasonic amplitude on tearing size.

The tearing forces under different ultrasonic amplitudes are illustrated in Fig. 13. The tearing forces do not vary substantially with the variation of ultrasonic amplitude. Only a tiny decrease of tearing forces with the rising ultrasonic amplitude can be distinguished. That indicates that the decrease of drilling force is not the major cause of the reduction of tearing force when a larger ultrasonic amplitude is applied. In RUM, the diamond grits electroplated on the end face drive the bulk of material removal. Their periodic impact on the material induces the fiber fracture. The diameter of a single carbon fiber in $\mathrm{C} / \mathrm{SiC}$ is about $5 \mu \mathrm{m}$, the same order of magnitude as the ultrasonic amplitude. When the ultrasonic amplitude increases, the fiber is more easily being cut off.

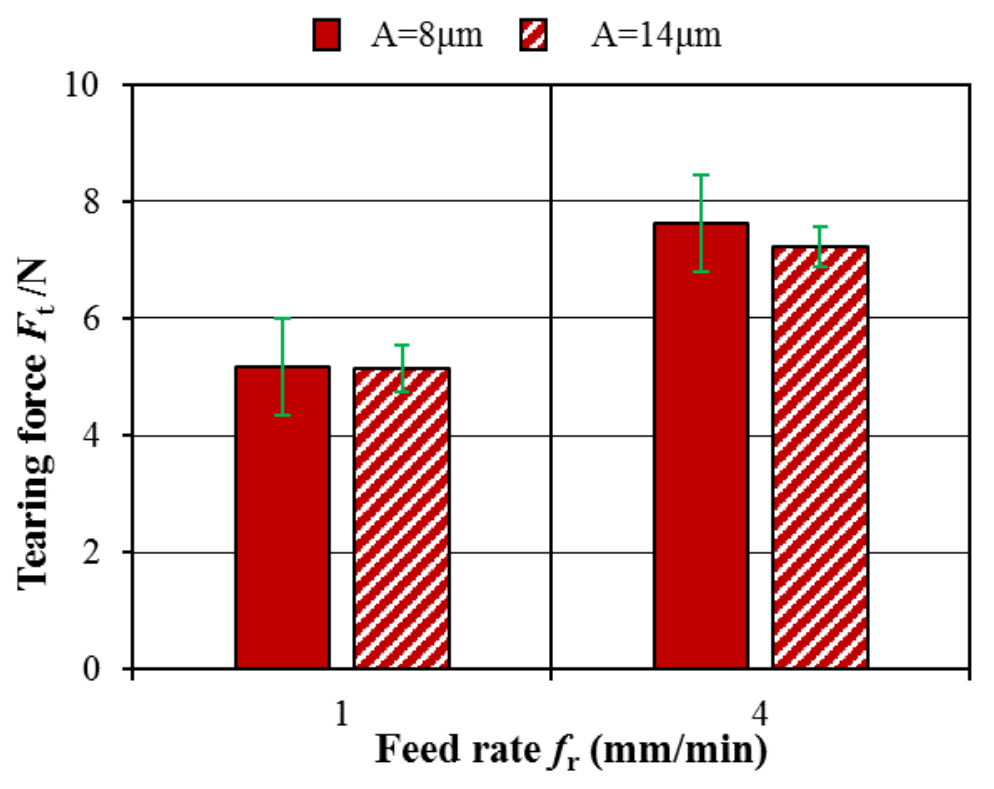

Fig. 13 Effect of ultrasonic amplitusde on tearing force. 


\section{Concluding remarks}

In this study, a novel compound step-taper diamond core drill for rotary ultrasonic machining (RUM) of $\mathrm{C} / \mathrm{SiC}$ was used to improve hole exit quality. Contrastive machining tests were conducted to evaluate the effectiveness of the new type of drill. The mechanism of tearing size reduction using the compound drill was revealed through detailed observation of the thrust force.

(1) Experimental results show that the compound drill is effective for the reduction of tearing size at the hole exit in RUM of $\mathrm{C} / \mathrm{SiC}$ composites. The compound drill can help reduce the tearing size by approximately $30 \%$ on average. This reduction effect is more significant when the spindle speed is low.

(2) Processing variables significantly affect tearing size when the common drill is used, the tearing size increases with increasing feed rate and decreasing spindle speed. When the compound drill is used, however, these dependencies are dramatically reduced. Results of variance analysis support this finding, indicating that the compound drill is more adaptable to workers with low experience.

(3) The tearing size reduction using the compound drill is due to the reprocessing effects of its taper face. In the reprocessing process of the taper face, the thrust force gradually decreases at the hole exit. The role of the step is to separate the tearing and reprocessing processes thoroughly.

(4) Increasing the ultrasonic amplitude can help further improve the hole exit quality when using the compound drill.

\section{Acknowledgements}

We gratefully acknowledge the financial support for this research from the Beijing Natural Science Foundation (Grant No. 3141001), the National Natural Science Foundation of China (Grant No.51475260), the National Science Foundation of China (Grant No. U1430116).

\section{References}

1. M.L. Wu, C.Z. Ren, H.Z. Xu. Comparative study of micro topography on laser ablated C/SiC surfaces with typical uni-directional fibre ending orientations, Ceram. Int. 42(7) (2016) 79297942.

2. H. Mei, H. Li, Q. Bai. Increasing the strength and toughness of a carbon fiber/silicon carbide composite by heat treatment, Carbon 54 (2013) 42-47.

3. H.B. Guo, P.R. Jia, B. Wang. Characterisation and analysis of the damage coupling effects of a 2D-C/SiC composite under proportional loading conditions, Ceram. Int. 42(1) (2016) 1007-1014.

4. L. Zhang, C. Ren, C. Ji. Effect of fiber orientations on surface grinding process of unidirectional C/SiC composites, Appl. Surf. Sci. 366(15) (2016) 424-431.

5. K. Ding, Y. Fu, H. Su. Experimental studies on drilling tool load and machining quality of C/SiC composites in rotary ultrasonic machining, J. Mater. Process. Tech. 214(12) (2014) 2900-2907.

6. S. Yuan, H. Fan, M. Amin. A cutting force prediction dynamic model for side milling of ceramic matrix composites $\mathrm{C} / \mathrm{SiC}$ based on rotary ultrasonic machining, Int. J. Adv. Manuf. Tech. (2015) 1-12. doi:10.1007/s00170-015-8099-6

7. Z.C. Li, Y. Jiao, T.W. Deines. Rotary ultrasonic machining of ceramic matrix composites: feasibility study and designed experiments, Int. J. Mach. Tool. Manu. 45(12) (2005) 1402-1411. 
8. E. Bertsche, K. Ehmann, K. Malukhin. Ultrasonic slot machining of a silicon carbide matrix composite, Int. J. Adv. Manuf. Tech. 66(5-8) (2013) 1119-1134.

9. X. Cao, B. Lin, X. Zhang. A study on grinding surface waviness of woven ceramic matrix composites, Appl. Surf. Sci. 270 (2013) 503-512.

10. T. Tawakoli, B. Azarhoushang. Intermittent grinding of ceramic matrix composites (CMCs) utilizing a developed segmented wheel, Int. J. Mach. Tool. Manu. 51(2) (2011) 112-119.

11. T. Tashiro, J. Fujiwara, Y. Takenaka. Grinding of C/C-SiC composite in dry method. Springer London, (2007) pp.351-352.

12. X. Cao, B. Lin, Y. Wang. Influence of diamond wheel grinding process on surface microtopography and properties of SiO 2/SiO 2 composite, Appl. Surf. Sci. 292 (2014) 181-189.

13. X. Cao, B. Lin, X. Zhang. Investigations on grinding process of woven ceramic matrix composite based on reinforced fiber orientations, Compos Part B-Eng. 71 (2015) 184-192.

14. M. Ramulu, H.W. See, D.H. Wang. Machining of ceramic composite TiB2/SiC by spark erosion, ASME Manu. Rev. 3 (2) (1990) 123-129.

15. I.P. Tuersley, A.P. Hoult, I.R. Pashby, Processing of a magnesiumalumina-silicate matrix, SiC fibre glass-ceramic matrix composite using a pulsed Nd-YAG laser part I optimization of pulse parameters, J. Mater. Sci. 31 (15) (1996) 4111-4119.

16. G. Hamatani, M. Ramulu, Machinability of high temperature composites by abrasive water jet, J. Eng. Mater.-T. ASME. 112 (4) (1990) 381-386.

17. H. Hocheng, N.H. Tai, C.S. Liu. Assessment of ultrasonic drilling of C/SiC composite material, Compos. Part A-Appl. S. 31(2) (2000) 133-142.

18. H. Li, B. Lin, S. Wan. An Experimental Investigation on Ultrasonic Vibration-Assisted Grinding of $\mathrm{SiO} 2 \mathrm{f} / \mathrm{SiO} 2 \quad$ Composites, Mater. Manuf. Process. (2015) 1-9. doi:10.1080/10426914.2015.1090586

19. Y. Wang, V.K. Sarin, B. Lin. Feasibility study of the ultrasonic vibration filing of carbon fiber reinforced silicon carbide composites, Int. J. Mach. Tool. Manu. 101 (2016) 10-17.

20. J. Wang, P. Feng, J. Zhang. Modeling the dependency of edge chipping size on the material properties and cutting force for rotary ultrasonic drilling of brittle materials, Int. J. Mach. Tool. Manu. 101 (2016) 18-27.

21. J. Wang, H. Zha, P. Feng. On the mechanism of edge chipping reduction in rotary ultrasonic drilling: a novel experimental method, Precis. Eng. 44 (2016) 231-235. 